\title{
Correlation of Salivary Glucose Level with Blood Glucose Level in Diabetes Mellitus
}

\author{
Arati S. Panchbhai ${ }^{1}$ \\ ${ }^{1}$ Department of Oral Medicine and Radiology, Sharad Pawar Dental College and Hospital, DMIMS University, Sawangi- \\ Meghe, Wardha, India.
}

\author{
Corresponding Author: \\ Arati S. Panchbhai \\ Shantiniketan Apartment, Flat-6, Jail Road, PIN code: 442001, Wardha (Maharastra) \\ India \\ E-mail: artipanch@gmail.com
}

\begin{abstract}
Objectives: There is alarming rise in number of people with diabetes mellitus over these years. If glucose in saliva is linked to glucose in blood it can be used to detect diabetes mellitus at an early stage. The present study is undertaken with the aim to assess the correlation of salivary glucose level with blood glucose level in people with diabetes mellitus.

Material and Methods: For investigations, 2 sets of samples of people with diabetes and the age and sex matched nondiabetic subjects were recruited. The salivary glucose was analyzed in unstimulated whole saliva samples using glucose oxidase method. Pearson's correlation coefficient test was applied to assess the correlation between salivary glucose level and blood glucose level.

Results: The significant $(\mathrm{P}<0.05)$ positive correlation of salivary glucose level and fasting blood glucose level was observed in people with uncontrolled diabetes in both the sets of samples.

Conclusions: Although study suggests some potential for saliva as a marker in monitoring of diabetes mellitus, there are many aspects that need clarification before we reach to a conclusion.
\end{abstract}

Keywords: diabetes mellitus type I; diabetes mellitus type II; patient selection; salivation; blood glucose.

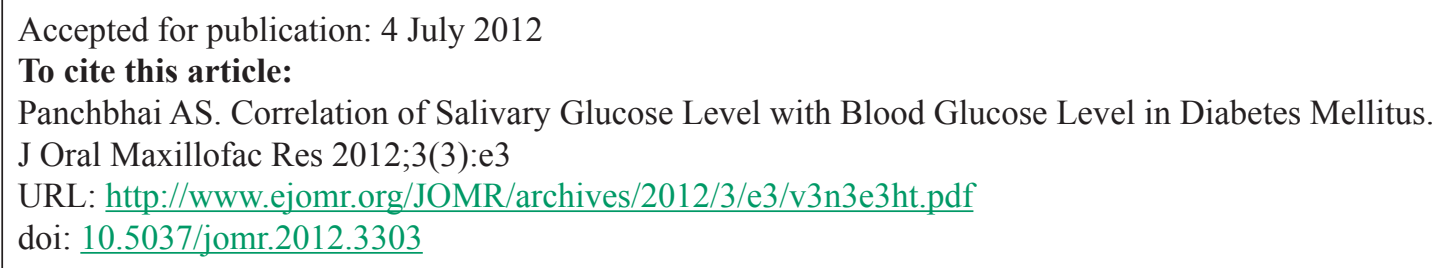




\section{INTRODUCTION}

India is likely to face the epidemic of diabetes mellitus in elderly population $[1,2]$. Oral physicians are liable to come in contact with significant number of patients with diabetes mellitus owing to the plethora of oral manifestations that are seen in diabetes mellitus. The global prevalence of diabetes is $6.4 \%$ in adult population. Worldwide, the number of people with diabetes is expected to grow to 438 million by 2030 , corresponding to $7.8 \%$ of the adult population. Type 2 diabetes mellitus is the fifth most common condition and the sixth leading cause of mortality amongst the elderly [3] . Asian Indians are at greater risk of developing diabetes. India is world's second most populous country with significant number of patients with type 2 diabetes than any other nation $[1,4]$. According to WHO estimate, $70 \%$ diabetics reside in developing countries, India has world's largest diabetes population with 50.8 million people suffering from diabetes followed by China [2] In 2025, approximately 57.2 million diabetics will be noticed in India [4].

Owing to lack of sufficient diagnosis and treatment, diabetes is a major cause of death worldwide, more than half of the diabetics remain undiagnosed especially the patients with Type 2 diabetes. Without timely diagnosis, complications and morbidity from diabetes rise exponentially [2].

While the early diagnosis of diabetes is essential to prevent its devastating complications, the current method of investigation needs the painful needleprick to withdraw blood, which may discourage the individuals from the investigation.
Most of the previous studies have demonstrated the raised salivary glucose level in diabetes [5-14]. However, there are very few reports on correlation of salivary glucose level (SGL) and blood glucose level (BGL) in diabetes.

The aim of the present study was to investigate the correlation between salivary glucose levels with blood glucose levels in people with diabetes mellitus.

\section{MATERIAL AND METHODS}

The present collaborative study was conducted in the department of Oral Medicine and Radiology, Sharad Pawar Dental College and Hospital, with Central Research Laboratory, Sawangi-Meghe. For the study, the subjects were recruited from Acharya Vinoba Bhave Rural Hospital, Sawangi-Meghe (Wardha).

The study was carried out in 2 sets of samples. Eighty diabetics were divided into 2 groups of 40 each, group with uncontrolled diabetes as group 1 and group with controlled diabetes as group 2, and group 3 is healthy non-diabetic group, formed of 40 age and gendermatched healthy non-diabetic subjects. The second set of sample consists of 150 study subjects in group of 50 each as in earlier sample. Age distribution and gender distribution of the study subjects in both the sets of samples is summarized in Table 1.

\section{Subject criteria}

1. For group of people with diabetes, fasting and post meal blood glucose levels were done and in healthy subjects, random blood glucose level was done to verify them as non-diabetic.

Table 1. Gender wise and age wise distribution of study subjects in 2 study sample sets groups

\begin{tabular}{|c|c|c|c|c|}
\hline \multirow{2}{*}{ Groups } & \multicolumn{3}{|c|}{ Gender wise distribution } & \multirow{2}{*}{$\begin{array}{c}\text { Age wise distribution (years) } \\
\text { M (SD, range) }\end{array}$} \\
\hline & $\mathbf{N}$ & Male (\%) & Female (\%) & \\
\hline \multicolumn{5}{|l|}{ Sample set 1} \\
\hline Group 1: with uncontrolled diabetes & 40 & $22(55)$ & $18(45)$ & $48.5(7.86,26-62)$ \\
\hline Group II: with controlled diabetes & 40 & $25(62.5)$ & $15(37.5)$ & $49.5(10.88,13-69)$ \\
\hline Group III: healthy non-diabetics & 40 & $16(40)$ & $24(60)$ & $46.1(10.25,17-65)$ \\
\hline \multirow[t]{2}{*}{ Total } & 120 & $63(52.5)$ & $57(47.5)$ & $45.9(10.93,13-69)$ \\
\hline & \multicolumn{3}{|c|}{$\mathrm{k}^{2}=4.46 ; \mathrm{df}=2 ; \mathrm{P}=0.12^{\mathrm{a}}$} & $\mathrm{F}=11.28 ; \mathrm{df}=2 ; \mathrm{P}=0.32^{\mathrm{a}}$ \\
\hline \multicolumn{5}{|l|}{ Sample set 2} \\
\hline Group 1: with uncontrolled diabetes & 50 & $26(52)$ & $24(48)$ & $49.4(9.81,22-71)$ \\
\hline Group II: with controlled diabetes & 50 & $28(56)$ & $22(44)$ & $49.1(11.51,11-71)$ \\
\hline Group III: healthy non-diabetics & 50 & $22(44)$ & $28(56)$ & $40.8(12.57,17-72)$ \\
\hline \multirow[t]{2}{*}{ Total } & 150 & $76(50.7)$ & $74(49.3)$ & $46.4(11.96,11-72)$ \\
\hline & \multicolumn{3}{|c|}{$\mathrm{k}^{2}=1.49 ; \mathrm{df}=2 ; \mathrm{P}=0.29^{\mathrm{a}}$} & $\mathrm{F}=9.14 ; \mathrm{df}=2 ; \mathrm{P}=0.86^{\mathrm{a}}$ \\
\hline
\end{tabular}

${ }^{a}$ No statistically significant at the level $\mathrm{P}>0.05$

$\mathrm{N}=$ number of subjects in each group; $\mathrm{P}=$ probability value; $\mathrm{M}(\mathrm{SD})=$ mean (standard deviation); $\boldsymbol{\aleph}^{2}=$ Chi-Square; $\mathrm{F}=\mathrm{ANOVA}$. 
2. For diagnosis, the status of diabetes mellitus was determined as per the criteria by The Expert Committee on Diagnosis and classification of Diabetes mellitus, 1998 [15], and the patients were approved by medical faculty with features of polyuria, polydypsia, polyphagia and raised blood glucose levels than normal level.

3. Patients with severe diabetic complications were excluded.

4. Study participants with any other systemic illness or on medications other than for diabetes were avoided.

Initially, having consented to study protocol, each participant underwent thorough oral and general examination and case history was recorded. The blood samples and unstimulated saliva samples were obtained for each participant.

\section{Salivary sample collection}

The saliva collection was standardized as far as possible. In this study, the unstimulated whole saliva $[\underline{8}, \underline{16-}$ 18] was taken for the estimation of salivary glucose as with stimulation there are alteration in the salivary composition $[19,20]$, hence the diagnostic possibility lies more with unstimulated saliva than stimulated saliva.

Salivary sample collection was done in the morning between 8.00 - 11.00 a.m. with study subjects sitting upright in a comfortable position in calm isolated room. Study subjects were instructed not to smoke or brush or eat or drink two hours prior to the time of saliva collection. Denture wearers were asked to remove dentures before the saliva collection.

In the beginning, subjects were asked to spit out or swallow whatever saliva was present in the mouth and the samples collected for initial 30 seconds were discarded. Salivary samples were collected in the icechilled graduated saliva collector by spitting method. Saliva collection was done at least for five minutes. Thus, the unstimulated whole saliva was collected $[\underline{3}, 5,6,8,18,21,22]$.

To start with, the study samples were centrifuged in the semiautomatic analyzer (Biotron BTR 830, Biosystems, USA). For that $1 \mathrm{ml}$ of each unstimulated salivary sample was centrifuged at 3000 rotations per minute for 20 minutes and soon the clear supernatant were processed for estimation of salivary glucose $[\underline{3}, \underline{21}, \underline{23}]$.

\section{Salivary glucose estimation Materials used}

For glucose estimation kit of Glucose oxidase, End point assay (Autospan-Cogent, Span Diagnostics, Surat-India) was used.

\section{Procedure for salivary glucose estimation}

In the present study, salivary glucose was analyzed by glucose oxidase end point assay $[\underline{5}, \underline{6}, \underline{11}, \underline{16}, \underline{24}, \underline{25}]$. At start, $1000 \mu \mathrm{l}$ of reagent solution was pipetted in each of the 2 test tubes. In one of test tubes, $10 \mu 1$ of standard was added and in the other, $10 \mu 1$ of salivary test sample was added, mixed well. To begin with the procedure, $1000 \mu 1$ of blank reagent was aspirated in the analyzer, followed by the standard solution and lastly, the test sample was aspirated and the readings were noted for both.

\section{Statistical analysis}

Diabetic groups with healthy non-diabetic group were compared using pairwise multiple comparisons analysis of variance (ANOVA) followed by a post hoc Dunnett's procedure. The normal distribution of the variables was confirmed by Kolmogorov-Smirnov test. $\aleph^{2}=$ ChiSquare test was applied for nonparametric variables. Pearson's correlation coefficient test was applied to assess the correlation between SGL and BGL. The data were expressed as mean (standard deviation [SD]) and in the entire tests $\mathrm{P}$ (probability) value $\leq 0.05$ was taken to be statistically significant. For statistical analysis, the SPSS Version 18.0 (IBM ${ }^{\circledR}$, Chicago, Illinois, USA) software package was used.

\section{RESULTS}

The results of distribution of blood glucose level and salivary glucose level in two study sample sets groups are shown in Table 2. The significant positive correlation between salivary glucose levels and the fasting blood glucose levels was seen in group with uncontrolled diabetes in the present study (Table 3). The results were insignificant for post meal BGL and random BGL as well as for controlled group and healthy non-diabetic group. The results were also insignificant when correlation was assessed according to gender.

\section{DISCUSSION}

The correlation between SGL and BGL is supported by various studies $[\underline{5}, \underline{8}, 10-14]$, whilst other study outcomes were in contradiction to this $[\underline{6}, \underline{22}, \underline{25}, 26]$. The significantly higher mean SGL was found in group with diabetes compared to healthy non-diabetic group. Overall, there is rich data on the estimation of SGL in diabetics but few researches have studied correlation between SGL and BGL, suggesting the paucity of literature on this aspect. 
Table 2. Distribution of blood glucose level and salivary glucose level in 2 study sample sets groups

\begin{tabular}{|c|c|c|c|c|c|c|}
\hline & \multicolumn{3}{|c|}{ Blood glucose level (mmol/l) } & \multicolumn{3}{|c|}{ Salivary glucose level (mmol/l) } \\
\hline Parameter & Groups & $\begin{array}{c}\text { Sample set } 1 \\
(\mathrm{n}=40 \text { each) } \\
M(\mathrm{SD})\end{array}$ & $\begin{array}{c}\text { Sample set } 2 \\
(\mathrm{n}=50 \text { each }) \\
\text { M (SD) }\end{array}$ & Groups & $\begin{array}{c}\text { Sample set } 1 \\
(n=40 \text { each }) \\
M(S D)\end{array}$ & $\begin{array}{c}\text { Sample set } 2 \\
(\mathrm{n}=50 \text { each }) \\
M(\mathrm{SD})\end{array}$ \\
\hline \multirow{2}{*}{ Fasting } & Uncontrolled diabetes & $10.45(69.72)$ & $10.43(66.8)$ & \multirow{2}{*}{ Uncontrolled diabetes } & \multirow{2}{*}{$0.45(6.45)$} & \multirow{2}{*}{$0.44(5.99)$} \\
\hline & Controlled diabetes & $6.83(13.02)$ & $5.74(13.28)$ & & & \\
\hline \multirow{2}{*}{ Post meal } & Uncontrolled diabetes & $17.53(86.03)$ & $17.50(80.04)$ & \multirow{2}{*}{ Controlled diabetes } & \multirow{2}{*}{$0.42(6.44)$} & \multirow{2}{*}{$0.37(6.16)$} \\
\hline & Controlled diabetes & $9.07(29.54)$ & $9.13(29.32)$ & & & \\
\hline Random & Healthy non-diabetics & $5.24(11.73)$ & $5.38(14.58)$ & Healthy non-diabetics & $0.11(1.44)$ & $0.13(2.02)$ \\
\hline
\end{tabular}

$\mathrm{n}=$ number of subjects, $\mathrm{M}(\mathrm{SD})=$ mean $($ standard deviation $) ; \mathrm{mmol} / \mathrm{l}=$ millimoles per litre.

Table 3. Intragroup correlation of salivary glucose level with blood glucose level in 3 study groups

\begin{tabular}{|c|c|c|c|c|c|c|c|}
\hline \multirow{3}{*}{$\begin{array}{c}\text { Pearson } \\
\text { correlation test }\end{array}$} & \multirow{3}{*}{ Parameter } & \multicolumn{3}{|c|}{ Sample set 1} & \multicolumn{3}{|c|}{ Sample set 2} \\
\hline & & \multicolumn{3}{|c|}{ Blood glucose (mmol/l) } & \multicolumn{3}{|c|}{ Blood glucose (mmol/l) } \\
\hline & & Fasting & Post meal & Random & Fasting & Post meal & Random \\
\hline $\begin{array}{c}\text { Subjects with } \\
\text { uncontrolled } \\
\text { diabetes }\end{array}$ & \multirow{3}{*}{$\begin{array}{c}\text { Salivary } \\
\text { glucose } \\
\text { (mmol/l) } \\
\text { r (P values) }\end{array}$} & $0.32\left(0.04^{\mathrm{a}}\right)$ & $-0.01\left(0.94^{b}\right)$ & - & $0.36\left(0.009^{\mathrm{a}}\right)$ & $0.02\left(0.863^{b}\right)$ & - \\
\hline $\begin{array}{c}\text { Subjects with } \\
\text { controlled } \\
\text { diabetes }\end{array}$ & & $-0.25\left(0.11^{b}\right)$ & $0.13\left(0.41^{\mathrm{b}}\right)$ & - & $-0.26\left(0.065^{b}\right)$ & $-0.13\left(0.337^{b}\right)$ & - \\
\hline $\begin{array}{l}\text { Healthy non- } \\
\text { diabetics }\end{array}$ & & - & - & $0.16\left(0.51^{b}\right)$ & - & - & $-0.06\left(0.967^{b}\right)$ \\
\hline
\end{tabular}

aStatistically significant at the level $\mathrm{P} \leq 0.05$.

${ }^{b}$ No statistically significant at the level $\mathrm{P}>0.05$ (Pearson correlation test).

$\mathrm{r}=$ Correlation coefficient; $\mathrm{mmol} / \mathrm{l}=$ millimoles per litre.

Diabetes mellitus is certain to be one of the fundamental challenges to the health professionals for twenty first century. The two key aspects of diabetic management are normalization of blood glucose level and its judicious monitoring; both of these need the patient's regular compliance. It is utmost important for diabetics to maintain the blood glucose level to normal throughout their lifespan as that indeed has impact on the risk of development of complications.

The present method of blood glucose estimation needs the venepuncture, which is highly traumatic to the patients at times, especially to the children. Apart from physical trauma, process also renders mental trauma and anxiety about the procedure to discourage the patients further. It is high time that the gravity of this problem be assessed so as to make the blood glucose analysis more acceptable to the patients which will not hamper their regular visit to diabetic clinic. In view of this, it is obligatory to establish the method that will non-invasively measure BGL.

In the same attempt, author aimed to evaluate the correlation between BGL and SGL, that will enable us to discuss whether SGL correspond to BGL or not. The important criterion to choose the glucose in saliva to measure the blood glucose is that, saliva is said to be the ultra filtrate of blood. Glucose is one of the blood components that are transferable across the salivary gland epithelium in proportion to its concentration in blood $[18,27]$. Secondly, whole saliva is the biologic fluid that is simple to collect.

Probably Kortuem [17] first studied correlation between BGL and SGL in 1944, followed by Shannon et al. [24] in 1960. Later on, Englander et al. [12] in 1963 and Campbell [16] in 1965 shed light on it. Englander et al. [12] collected blood and saliva glucose samples for half, 1, 2, and 3 hours. Although at lower magnitude, glucose concentration in parotid saliva varied directly with plasma concentration for each subjects. But as there was considerable overlapping of glucose values in individuals with diabetes and in healthy groups, they were in doubt whether saliva could be useful to replace plasma [12]. While Yamaguchi et al. [14] preferred to use submandibular or sublingual salivary samples instead of parotid saliva for estimating BGL as daily variations in the correlation between BGL and parotid saliva glucose level were too large.

Previously, authors showed significant positive correlation of BGL and SGL [ 8$]$ ]. But the observation 
that individuals with diabetes who are denture wearers had higher SGL than non-denture wearers made them to propose that there could be additional contributory factors that may raise glucose in saliva apart from the basement membrane permeability [ $[\underline{8}$.

The correlation was also studied in children with diabetes and it was found to be significant, though of little magnitude $[\underline{10}, \underline{11}]$.

Newly, salivary glycated proteins were estimated instead of salivary glucose and the correlation between salivary glycated proteins (SGP) and blood glycated proteins (BGP) were perceived. Blood glucose, haemoglobin $\mathrm{A} 1 \mathrm{c}(\mathrm{HbA} 1 \mathrm{c})$, and fructosamine were measured as indices of BGP. Fructosamine and hydrazine method were used to measure SGP. Saliva fructosamine glycated protein showed significant correlation with $\mathrm{HbA1c}$ and blood glucose. Hence they concluded that BGP and blood glucose could be estimated by measuring SGP using fructosamine method [28].

Conversely, some of the studies have contradicted the correlation between SGL and BGL $[9,22,25,26]$. It was suggested that saliva cannot be implemented to indicate BGL in diabetics as the amount of damage to the salivary gland in turn the quantity of leakage of glucose from plasma to saliva is unpredictable $[\underline{22}, \underline{26}]$. Twetman et al. [9] justified the threshold mechanisms along the basement membrane; hence rejected the possibility of existence of any relationship between serum and saliva glucose. Other study results were in accordance with this findings $[\underline{7}, \underline{22}, 25]$.

Lack of correlation between saliva glucose and plasma glucose was observed by Marchetti et al. [26] in fasting state in both diabetics and non-diabetics and they indicated that degree of metabolic control doesn't affect the way in which salivary glands handle the glucose. This finding is in contradiction to present study result. Nonetheless, majority of the studies supported the correlation between SGL and BGL. Although, it is apparent that SGL may replace BGL, there are some concerns that needed to be revealed here.

Most importantly, the raised glucose level is also recorded in gingival fluid, thus the glucose in saliva may not be exclusively of salivary gland origin. In the research work carried out so far, there is no uniformity in the methodology used for salivary glucose estimation. Salivary samples used were assorted as either whole saliva or saliva collected from the individual salivary glands; stimulated or unstimulated saliva was used. Accordingly techniques for saliva collection also differed.

Factors attributed to patients were the difference in duration of diabetes, the glycemic control measures used and the variable sample size. There were disparity in the age range, clinical status, diet, life style and the socioeconomic status of the patients. Apart from these, the metabolic state of diabetics may be obscure such as, diabetics were uncontrolled or poorly controlled, well controlled, fairly or acceptably controlled. Besides, no consideration was given to metabolic states such as impaired glucose tolerance or impaired fasting glucose. Such patients may develop diabetes in 10 years [29]. It was also shown that SGL was higher in patients with impaired glucose tolerance as similar to that observed in with diabetes [30].

If the correlation does exist between SGL and BGL, then it should have been observed for fasting, post meal as well as for random BGL and thus for all the study groups.

The correlation between SGL and BGL cannot be justified until the salivary glucose estimation is authenticated. There should be homogeny in the methodology used plus the study samplings need to be standardized to have the study outcomes which will be comparable and sustainable.

Initially, basement membrane permeability was thought to be the cause of raised SGL, contrarily, studies suggested the threshold mechanism along gland basement membrane as the magnitude of leakage of glucose from plasma to saliva cannot be predicted [19]. Also, the difference did not demonstrate linear relations between the increase of SGL and BGL. These studies turned down the possibility of any relationship between serum and saliva glucose concentration. Additionally, how intraglandular carbohydrate mechanism influences the SGL needs to be analyzed. Besides, glucose may be a source of nutrient to the microbes in the oral cavity, therefore portion of the glucose in saliva might be being utilized in this manner to influence the total glucose content in saliva [31].

There has been continuing hope over many years that saliva could be an option to blood for diagnostic tests; if so then it would be simple, inexpensive, and simply non-invasive procedure to expect better conformity from the patients especially for the juveniles with diabetes. Moreover, it will be possible for the people with diabetes to self-monitor themselves with method that is easier and not painful. Type 2 diabetes may remain undetected for years. The simple procedure may enable even the healthy subjects to approach the diabetic clinic for routine check-up, thus the apparently healthy patients can get diagnosed for diabetes mellitus as earlier they get diagnosed, lesser will be the complications.

There are several factors that may influence SGL and eventually its correlation to BGL; unless these aspects are clarified salivary glucose cannot be employed in lieu of BGL. Subsequently, the diagnostic potential of SGL is in doubt for the near future.

India has distinction of being the country having higher 
prevalence of diabetes mellitus; the present study is of great concern in context to Indian population as well as globally to the countries with the greater prevalence of diabetes. The present study highlights the importance of early diagnosis and the utilization of non-invasive saliva analysis over the invasive blood analysis. To our knowledge, present research is one of those few studies that have included the evaluation of the critical correlation of SGL and BGL. In addition, the study compared the subjects according to gender for correlation; the data for which is meagre; though the findings were insignificant. Although the study results were inconclusive and with shortcoming of relatively insufficient sample size, nonetheless, the study has unquestionably put forth some observations deserving explanation, which likely suggests enormous scope for further research.

\section{CONCLUSIONS}

The salivary glucose level and blood glucose level correlation analysis in the present study could not establish a consistent parameters relationship in all the study groups. However, there are many issues that need consideration and further exploration, which recommends extensive and highly structured research before we reach to any conclusion.

\section{ACKNOWLEDGMENTS AND DISCLOSURE STATEMENTS}

The author declares no competing interest or conflict of interest.

\section{REFERENCES}

1. Diamond J. Medicine: diabetes in India. Nature. 2011 Jan 27;469(7331):478-9. [Medline: 21270882] [doi: $10.1038 / 469478 \mathrm{a}]$

2. Diabetes facts. In: IDF Diabetes Atlas. 2011 May. URL: http://www.idf.org/diabetesatlas

3. Chávez EM, Borrell LN, Taylor GW, Ship JA. A longitudinal analysis of salivary flow in control subjects and older adults with type 2 diabetes. Oral Surg Oral Med Oral Pathol Oral Radiol Endod. 2001 Feb;91(2):166-73. [Medline: 11174593]

4. Pendsey S. Gravity of problem. In: Practical management of diabetes. 2nd ed, New Delhi: Jaypee brothers; 2004. p. 7-12.

5. Pal P, Desai NT, Kannan N, Masur VN, Daniel MJ, Bhatt N. Estimation of salivary glucose, salivary amylase, salivary total protein and periodontal microflora in diabetes mellitus. J Indian Dent Assoc. 2003(74):143-9.

6. Thorstensson H, Falk H, Hugoson A, Olsson J. Some salivary factors in insulin-dependent diabetics. Acta Odontol Scand. 1989 Jun;47(3):175-83. [Medline: 2667279] [doi: 10.3109/00016358909007698]

7. Tenovuo J, Alanen P, Larjava H, Viikari J, Lehtonen OP. Oral health of patients with insulin-dependent diabetes mellitus. Scand J Dent Res. 1986 Aug;94(4):338-46. [Medline: 3489277]

8. Darwazeh AM, MacFarlane TW, McCuish A, Lamey PJ. Mixed salivary glucose levels and candidal carriage in patients with diabetes mellitus. J Oral Pathol Med. 1991 Jul;20(6):280-3. Review. [Medline: 1890663] [doi: 10.1111/j.1600-0714.1991.tb00928.x]

9. Twetman S, Nederfors T, Stahl B, Aronson S. Two-year longitudinal observations of salivary status and dental caries in children with insulin-dependent diabetes mellitus. Pediatr Dent. 1992 May-Jun;14(3):184-8. [Medline: 1528788]

10. Karjalainen KM, Knuuttila ML, Käär ML. Salivary factors in children and adolescents with insulin-dependent diabetes mellitus. Pediatr Dent. 1996 Jul-Aug;18(4):306-11. [Medline: 8857659]

11. López ME, Colloca ME, Páez RG, Schallmach JN, Koss MA, Chervonagura A. Salivary characteristics of diabetic children. Braz Dent J. 2003;14(1):26-31. Epub 2003 Jul 31. [Medline: 12656461] [doi: 10.1590/S0103-64402003000100005]

12. Englander HR, Jeffay AI, Fuller JB, Chauncey HH. Glucose concentrations in blood plasma and parotid saliva of individuals with and without diabetes mellitus. J Dent Res. 1963 Sep-Oct;42:1246. [Medline: 14061947] [doi: $10.1177 / 00220345630420052301]$

13. Amer S, Yousuf M, Siddqiui PQ, Alam J. Salivary glucose concentrations in patients with diabetes mellitus--a minimally invasive technique for monitoring blood glucose levels. Pak J Pharm Sci. 2001 Jan;14(1):33-7. [Medline: 16414850]

14. Yamaguchi M, Mitsumori M, Kano Y. Development of noninvasive procedure for monitoring blood glucose levels using saliva. Eng Med Biol Soc. 1998 Nov;(4):1763-6.

15. Manfredi M, McCullough MJ, Vescovi P, Al-Kaarawi ZM, Porter SR. Update on diabetes mellitus and related oral diseases. Oral Dis. 2004 Jul;10(4):187-200. Review. [Medline: 15196139] [doi: 10.1111/j.1601-0825.2004.01019.xx]

16. Campbell MJ. Glucose in the saliva of the non-diabetic and the diabetic. Patient. Arch Oral Biol. 1965 Mar-Apr;10:197-205. [Medline: 14272394] [doi: 10.1016/0003-9969(65)90020-8]

17. Kortuem GM. Saliva glucose and blood glucose. Am J Clin Pathol 1944; 14: 70.

18. Aydin S. A comparison of ghrelin, glucose, alpha-amylase and protein levels in saliva from diabetics. J Biochem Mol Biol. 2007 Jan 31;40(1):29-35.29-35. [Medline: 17244479] [doi: 10.5483/BMBRep.2007.40.1.029]

19. Ferguson DB. The physiology and biology of saliva. In: deBurgh Norman JE, McGurk M, editors. Color atlas and text of salivary gland: disease, disorders and surgery. London: Mosby-Wolfe; 1995. p. 40-8. 
20. Harrison R, Bowen WH. Flow rate and organic constituents of whole saliva in insulin-dependent diabetic children and adolescents. Pediatr Dent. 1987 Dec;9(4):287-91. [Medline: 3507647]

21. Moore PA, Guggenheimer J, Etzel KR, Weyant RJ, Orchard T. Type 1 diabetes mellitus, xerostomia, and salivary flow rates. Oral Surg Oral Med Oral Pathol Oral Radiol Endod. 2001 Sep;92(3):281-91. [Medline: 11552145]

22. Sharon A, Ben-Aryeh H, Itzhak B, Yoram K, Szargel R, Gutman D. Salivary composition in diabetic patients. J Oral Med. 1985 Jan-Mar;40(1):23-6. [Medline: 3855982]

23. Marder MZ, Abelson DC, Mandel ID. Salivary alterations in diabetes mellitus. J Periodontol. 1975 Sep;46(9):567-9. [Medline: 1057651]

24. Shannon IL, Prigmore JR, Brooks RA. Glucose concentrations in parotid fluid and blood serum following intravenous glucose loading. Oral Surg Oral Med Oral Pathol. 1960 Aug;13:1010-2. [Medline: 14445483] [doi: 10.1016/0030-4220(60)90048-7]

25. Forbat LN, Collins RE, Maskell GK, Sönksen PH. Glucose concentrations in parotid fluid and venous blood of patients attending a diabetic clinic. J R Soc Med. 1981 Oct;74(10):725-8. [Medline: 7288781] [FREE Full Text]

26. Marchetti P, Tognarelli M, Giannarelli R, Grossi C, Picaro L, di Carlo A, Benzi L, Ciccarone A, Navalesi R. Decreased salivary glucose secretory rate: usefulness for detection of diabetic patients with autonomic neuropathy. Diabetes Res Clin Pract. 1989 Sep 18;7(3):181-6. [Medline: 2605985] [doi: 10.1016/0168-8227(89)90003-X]

27. Gigi MK. Relations between blood and salivary glucose level in diabetic patients. Artikel Med Dent J. 2003 Aprl;36(2).

28. Nakamoto I, Morimoto K, Takeshita T, Toda M. Correlation between saliva glycated and blood glycated proteins. Environ Health Prev Med. 2003 Jul;8(3):95-9. [Medline: 21432106] [doi: 10.1007/BF02897922]

29. Mealy B. Diabetes mellitus. In: Greenberg MS, Glick M, editors. Burket's Oral Medicine Diagnosis and Treatment. New York: BC Decker Inc; 2003. p. 563-77.

30. Borg Andersson A, Birkhed D, Berntorp K, Lindgärde F, Matsson L. Glucose concentration in parotid saliva after glucose/food intake in individuals with glucose intolerance and diabetes mellitus. Eur J Oral Sci. 1998 Oct;106(5):931-7.

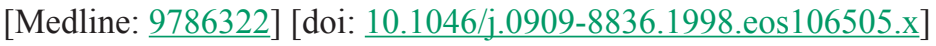

31. Jurysta C, Bulur N, Oguzhan B, Satman I, Yilmaz TM, Malaisse WJ, Sener A. Salivary glucose concentration and excretion in normal and diabetic subjects. J Biomed Biotechnol. 2009;2009:430426. Epub 2009 May 26. [Medline: 19503844] [FREE Full Text]

\section{To cite this article:}

Panchbhai AS. Correlation of Salivary Glucose Level with Blood Glucose Level in Diabetes Mellitus.

J Oral Maxillofac Res 2012;3(3):e3

URL: http://www.ejomr.org/JOMR/archives/2012/3/e3/v3n3e3ht.pdf

doi: $10.5037 /$ jomr.2012.3303

Copyright (C) Panchbhai AS. Accepted for publication in the JOURNAL OF ORAL \& MAXILLOFACIAL RESEARCH (http://www.ejomr.org), 4 July 2012

This is an open-access article, first published in the JOURNAL OF ORAL \& MAXILLOFACIAL RESEARCH, distributed under the terms of the Creative Commons Attribution-Noncommercial-No Derivative Works 3.0 Unported License, which permits unrestricted non-commercial use, distribution, and reproduction in any medium, provided the original work and is properly cited. The copyright, license information and link to the original publication on (http://www.ejomr.org) must be included. 